\title{
Intra-His Bundle Block. Clinical, Electrocardiographic, and Electrophysiologic Characteristics
}

\author{
Eduardo M. Andréa, Jacob Atié, Washington A. Maciel, Nilson A. de Oliveira Jr, \\ Luiz Eduardo Camanho, Luís Gustavo Belo, Hecio Affonso de Carvalho, \\ Leonardo Siqueira, Eduardo Saad, Ana Claudia Venancio
}

Rio de Janeiro, RJ - Brazil

Objective - To assess the clinical, electrocardiographic, and electrophysiologic characteristics of patients (pt) with intra-His bundle block undergoing an electrophysiologic study (EPS).

Methods - We analyzed the characteristics of 16 pt with second-degree atrioventricular block and symptoms of syncope or dyspnea, or both, undergoing conventional EPS.

Results - Intra-His bundle block was documented in 16 pt during an EPS. In 15 (94\%) pt, the atrioventricular block was recorded in sinus rhythm; 4 (25\%) pt had intra-His Wenckebach phenomenon, which correlated with Mobitz I (MI) atrioventricular block on the electrocardiogram. Seven (44\%) pt had 2:1 atrioventricular block, 2 of whom were asymptomatic $(12.5 \%)$. One (6\%) pt had intra-and infra-His bundle block. Clinically, 11 (68\%) pt had syncope or presyncope, $3(18 \%)$ had dyspnea on exertion, and $2(12.5 \%)$ were asymptomatic. Eight (50\%) pthad bundle-branch block as follows: 4 (25\%) pt had left bundle-branch block, and 4 (25\%) had right bundle-branch block. Left anterosuperior divisional block was observed in 3 pt (19\%), 2 of whom with associated right bundle-branch block.

Conclusion - Intra-His bundle block was observed in $11 \%$ of the pt with second-degree atrioventricular block, syncope or presyncope, or both, it being the most frequent clinical presentation. Intra-His bundle block was more common in the elderly (> 60years) and among females. The most frequent electrocardiographic presentations were second-degree Mobitz I or type 2:1 atrioventricular block.

Keywords: intra-His, atrioventricular block, syncope

Hospital Universitário Clementino Fraga Filho-UFRJ, Instituto Estadual de Cardiologia Aloysio de Castro, and Clínica São Vicente

Mailing address: Eduardo Machado Andréa - Rua Joaquim Moreira Neves, 295/ 102 - Rio de Janeiro, RJ, Brazil - 22795-460 - E-mail: eandrea@openlink.com.br English version by Stela Maris C. e Gandour
Atrioventricular block is a conduction disturbance at the axis formed by the atrium, AV node, His bundle, and its branches, which may vary from a mild delay in conduction (first-degree atrioventricular block) to a conduction block between atria and ventricles (second- and third-degree atrioventricular blocks) ${ }^{1}$.

Atrioventricular block may occur at the 3 following electrophysiological levels: atrioventricular node, within the His bundle, and below the His bundle ${ }^{2}$. These levels have anatomical correlation with, respectively, the atrioventricular node, the penetrating His bundle (within the central fibrous body), and nonpenetrating His bundle (out of the central fibrous body). First-degree atrioventricular block usually has a delay in the conduction within the atrioventricular node. In different series, total atrioventricular block has been reported at the 3 following levels: AV node (16 to $25 \%$ ), intra-His bundle (14 to $20 \%$ ), and infra-His bundle (56 to $68 \%)^{1-3}$. Some patients have simultaneous blocks at several levels (multilevel block) ${ }^{4}$.

Disturbances in the conduction of the His-Purkinje system have different electrocardiographic, electrophysiologic, and clinical manifestations ${ }^{5-10}$.

Intra-His bundle block evidenced on electrophysiologic study was first reported by Narula, Scherlag, and Samet in $1969^{11}$.

Our study aimed at retrospectively reporting the clinical, electrocardiographic, and electrophysiologic characteristics of a series of 16 patients with intra-His bundle block.

\section{Methods}

We assessed 146 patients with second-degree atrioventricular block on surface electrocardiography or 24-hour Holter monitoring; 16 of these patients showed intra-His bundle block on the electrophysiologic study.

Twelve-lead electrocardiography preceded the electrophysiologic study. Holter monitoring was performed with 
cassette magnetic tape recording in a modulated frequency. The material was analyzed with the Avionics analyzer with digital into analogical signs decoding, and printed as a standard 3-lead electrocardiogram.

The patients underwent an electrophysiologic study because of symptoms, such as dyspnea, and presyncope or syncope, and second-degree atrioventricular block. Two asymptomatic patients underwent the electrophysiologic study because 1 had second-degree Mobitz II atrioventricular block and the other patient had second-degree Mobitz I atrioventricular block, both with an A:V ratio of 3:2, 2:1 and a high-degree block during wakefulness.

The electrophysiologic study was performed after withdrawing antiarrhythmic drugs for 5 half-lives and after the patient's consent. The patients had to fast for 6 hours prior to the examination and were kept under mild sedation (midazolam, alfentanil or propofol, or both) and local anesthesia ${ }^{10}$. The femoral vein was punctured at 3 sites, three 6 French $(6 \mathrm{~F})$ quadripolar catheters were introduced and were positioned highly in the right atrium, adjacent to the septal leaflet of the tricuspid valve (His bundle potential recorded), and in the right ventricular apex.

Intracavitary bipolar electrograms (right atrium, His bundle 1 , His bundle 2 , and right ventricle) were simultaneously recorded with 6 surface leads (D1, D2, D3, V1, and V6) by the multichannel recorder of the EMS cardiac electrophysiology system with 20 - to $500-\mathrm{Hz}$ filters (fig. 1).

After recording all leads in sinus rhythm, the stimulation protocol was initially performed through the atrial cavity for the following analyses: sinus function (sinus recovery times of $100,120,140$, and 160 pulses $/ \mathrm{min}$ ), atrial electric stability (atrial stimulation with up to 3 extrastimuli in 600-, 500-, and 430-ms cycles and in sinus rhythm), AV nodal conduction, and His-Purkinje conduction.

The ventricular cavity was stimulated to assess ventricular-atrial conduction and ventricular electrical stability (up to 2 extrastimuli in the right ventricular apex in 600-, 500, and 430-ms cycles, coupled with sinus rhythm).

The normal His potential duration $(\mathrm{H})$ ranges from 15 to $20 \mathrm{~ms}^{2}$. Intra-His conduction disturbance on the electrophysiological study was characterized by the following: a) recording of $2 \mathrm{H}$ spikes ( $\mathrm{H} 1$ and $\mathrm{H} 2$ ) characterizing fragmentation of the His potential with $\mathrm{H} 1-\mathrm{H} 2$ recording time $\mathrm{m} 30 \mathrm{~ms}^{5}$ (fig. 2), and intra-His bundle block characterized by the presence of an $\mathrm{H} 1$ spike not followed by an $\mathrm{H} 2$ spike, recorded by a catheter with an interelectrode distance of $2 \mathrm{~mm}$ (fig. 3). The $\mathrm{H} 2$ spike, when present, was followed by the ventricular intracavitary potential (V), the H2V interval being $\mathrm{m} 35 \mathrm{~ms}^{12}$.

The difficulty in capturing the fragmented His bundle potential (HI-H2) may underestimate the true incidence of intra-His bundle block ${ }^{13}$. Two of the 16 patients had previous electrophysiologic studies with no evidence of intraHis conduction disturbance.

\section{Results}

Of the 16 patients studied, 11 had syncope or presyncope, 3 had dyspnea on exertion, and 2 were asymptomatic.

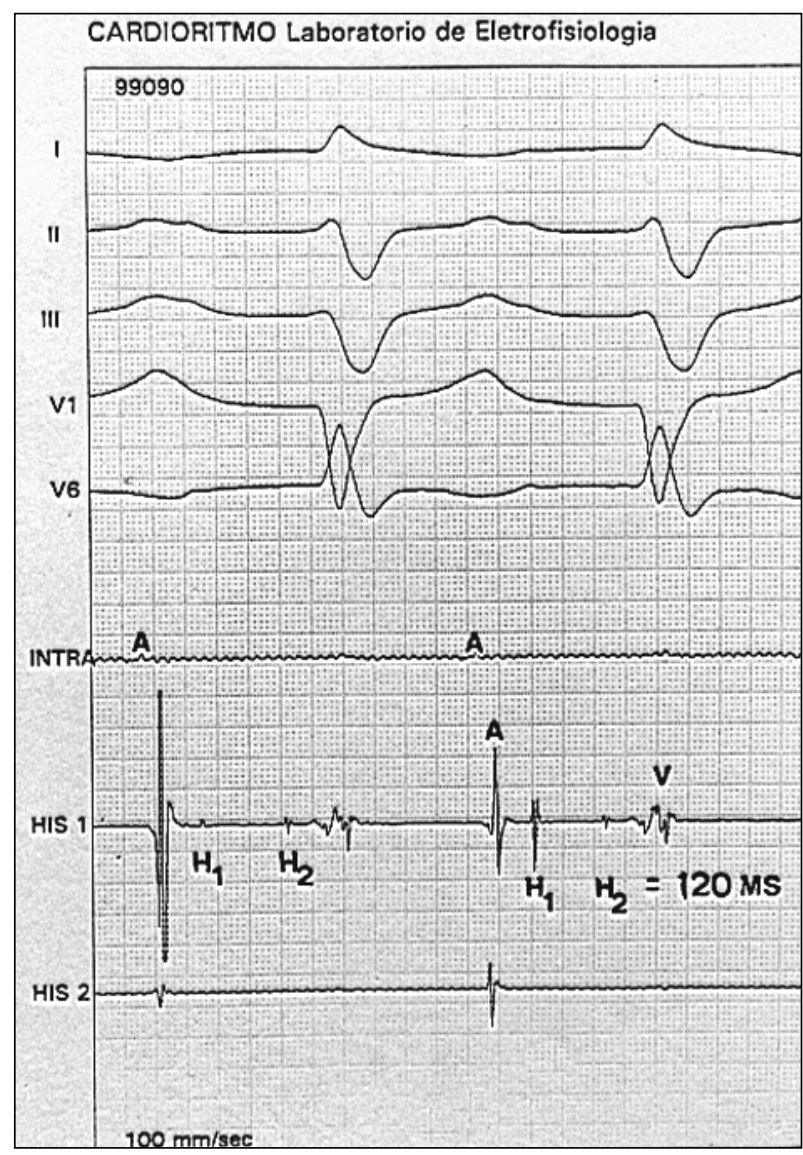

Fig. 1 - Simultaneous intracardiac and surface recording at the velocity of $100 \mathrm{~mm} / \mathrm{s}$ with: 5-lead electrocardiogram (I, II, III, V1, and V6) and 3 intracavitary recordings (INTRA, His1, and His2). The INTRA recording captures right atrial potential. Surface electrocardiography shows anterosuperior divisional block and the His 1 recording shows split His bundle potentials with an important conduction disturbance $(\mathrm{H} 1-\mathrm{H} 2=120 \mathrm{~ms})$. The $\mathrm{H} 2-\mathrm{V}$ interval is $40 \mathrm{~ms}$ (normal).

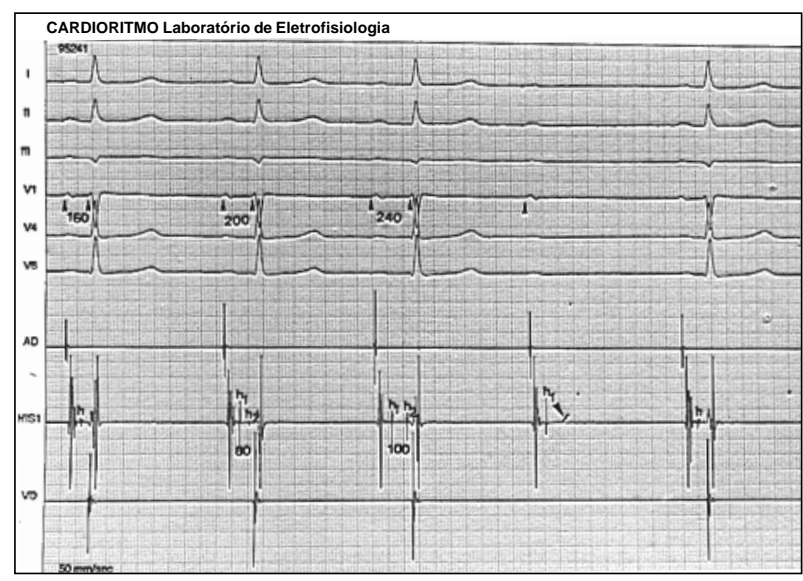

Fig. 2 - Simultaneous intracardiac and surface recording at the velocity of $50 \mathrm{~mm} / \mathrm{s}$ with: 6-lead electrocardiogram (I, II, III, V1, V4, and V6) and 3 intracavitary recordings (right atrium, His1, and right ventricle). The intracavitary recordings capture the right atrial, His bundle (His 1), and right ventricular potentials. The surface electrocardiogram shows second-degree Mobitz I atrioventricular block (A:V sequence 4:3 type) with narrow QRS complex, while the His1 recording characterizes Mobitz I as an intra-His bundle block (progressive increase in the $\mathrm{H} 1-\mathrm{H} 2$ interval until the $\mathrm{H} 2$ potential does not follow $\mathrm{H} 1$ ). The $\mathrm{H} 1$ potential is the proximal activation and the $\mathrm{H} 2$ is the distal activation of the His bundle. The measurements of the PR interval in the V1 lead and the $\mathrm{H} 1-\mathrm{H} 2$ interval in His 1 channel recording are in milliseconds. 


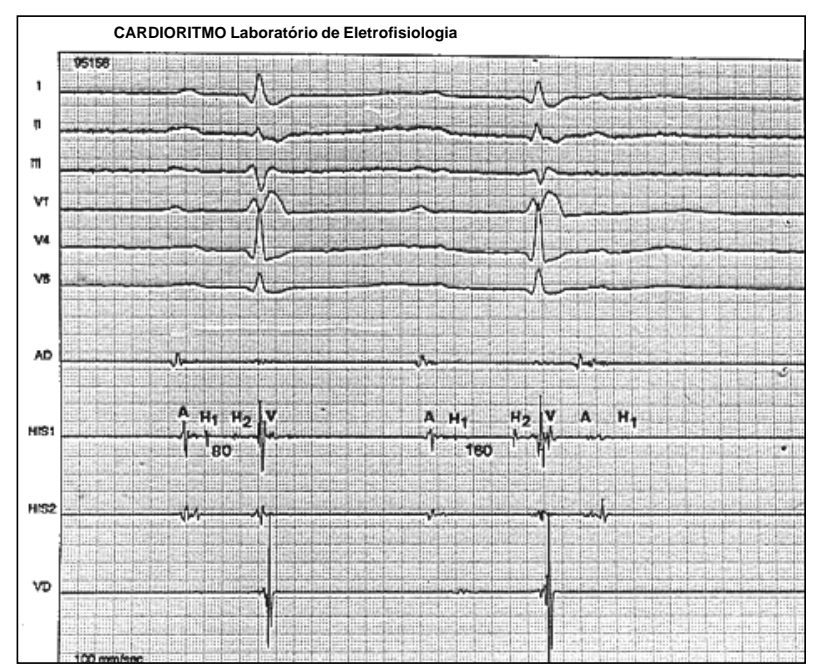

Fig. 3 - Simultaneous intracardiac and surface recording at the velocity of $100 \mathrm{~mm} / \mathrm{s}$ with: 6-lead electrocardiogram (I, II, III, V1, V4, and V6) and 4 intracavitary recordings (right atrium, His 1 , His 2 , and right ventricle). The intracavitary recordings capture the right atrial, distal, and proximal His bundle (His1 and His2), and right ventricular potentials. The surface electrocardiogram shows right bundlebranch block with second-degree Mobitz I atrioventricular block (A:V sequence $3: 2$ type), while the His 1 recording characterizes Mobitz I as an intra-His bundle block (progressive increase in the $\mathrm{H} 1-\mathrm{H} 2$ interval until the $\mathrm{H} 2$ potential does not follow $\mathrm{H} 1$ ). The $\mathrm{H} 2-\mathrm{V}$ interval is $35 \mathrm{~ms}$ (normal). The $\mathrm{H} 1$ potential is the proximal activation and the $\mathrm{H} 2$ is the distal activation of the His bundle. The measurements in the His1 channel recording are in milliseconds.

Their ages ranged from 25 to 88 (mean of 68.8 ) years. Ten patients were females and 6 were males. Five patients had hypertensive heart disease, 3 had previous left ventricular failure compensated at the time of the electrophysiological study, 1 patient had Sjögren's syndrome, and 7 patients had no structural heart disease (tab. I). Of the patients with previous left ventricular failure, 2 had idiopathic dilated cardiomyopathy, and 1 had ischemic heart disease.

The 12-lead electrocardiogram obtained at baseline during the electrophysiologic study showed the following: 1) second-degree Wenckebach or Mobitz I(MI) atrioventricular block in 4 patients, 3 of whom had a narrow QRS complex and another had right bundle-branch block; 2) seconddegree Mobitz II (M II) atrioventricular block associated with anterosuperior divisional block in 1 patient, right bundle-branch block associated with anterosuperior divisional block in 2 patients, isolated right bundle-branch block in 1 patient, isolated left bundle-branch block in 4 patients; 3 ) and electrocardiogram with no (atrioventricular and intraventricular) conduction disturbance in 4 patients.

Bundle-branch block was found in $8(50 \%)$ patients with equal distribution of left bundle-branch (4 patients) and right bundle-branch (4 patients) blocks. Anterosuperior divisional block was found in $3(18 \%)$ patients, 2 (12.5\%) of whom also had right bundle-branch block (tab. I).

Two of the 16 patients studied had type 2:1 or highdegree atrioventricular block during wakefulness (24-hour Holter) and were asymptomatic.

No electrocardiographic difference between the patients with and without structural heart disease was found.

Of the 146 patients with second-degree atrioventricular block, 16(11\%) had split His bundle potentials during the electrophysiologic study, and $\mathrm{H} 1$ potential not followed by $\mathrm{H} 2$ potential when the intra-His bundle block occurred.

In 15 of these $16(94 \%)$ patients, intra-His bundle block was recorded in sinus rhythm and in $1(6 \%)$ patient it occurred during programmed atrial stimulation.

Four (25\%) patients had decremental conduction with block (intra-His Wenckebach phenomenon). This phenomenon was characterized by a progressive increase in the $\mathrm{H} 1-\mathrm{H} 2$ interval until the $\mathrm{H} 1$ potential did not follow the $\mathrm{H} 2$ potential (figs. 2 and 3). These patients had second-degree Mobitz I atrioventricular block on electrocardiography.

\begin{tabular}{|c|c|c|c|c|c|c|c|c|c|c|c|c|c|c|c|}
\hline $\mathrm{Pt}$ & Age & Sex & Sync & Dysp & Asy & MI & MII & RBBB & ASDB & LBBB & QRSn & SAH & LVF & SS & Normal \\
\hline 1 & 25 & M & & $\mathrm{x}$ & & & & $\mathrm{x}$ & & & $\mathrm{x}$ & & & $\mathrm{x}$ & \\
\hline 2 & 59 & $\mathrm{~F}$ & $\mathrm{x}$ & & & $\mathrm{x}$ & & & & & $\mathrm{x}$ & & & & $\mathrm{x}$ \\
\hline 3 & 67 & $\mathrm{~F}$ & & & $\mathrm{x}$ & $\mathrm{x}$ & & & & & $\mathrm{x}$ & $\mathrm{x}$ & & & \\
\hline 4 & 68 & $\mathrm{~F}$ & $\mathrm{x}$ & & & $\mathrm{x}$ & & $\mathrm{x}$ & & & & & & & $\mathrm{x}$ \\
\hline 5 & 63 & M & $\mathrm{x}$ & & & $\mathrm{x}$ & & & & & $\mathrm{x}$ & & & & $\mathrm{x}$ \\
\hline 6 & 73 & $\mathrm{~F}$ & & & $\mathrm{x}$ & & $\mathrm{x}$ & & & & $\mathrm{x}$ & & & & $\mathrm{x}$ \\
\hline 7 & 79 & M & $\mathrm{x}$ & & & & $\mathrm{x}$ & & & & $\mathrm{x}$ & $\mathrm{x}$ & & & \\
\hline 8 & 68 & $\mathrm{~F}$ & $\mathrm{x}$ & & & & $\mathrm{x}$ & $\mathrm{x}$ & $\mathrm{x}$ & & & & & & $\mathrm{x}$ \\
\hline 9 & 88 & M & & $\mathrm{x}$ & & & $\mathrm{x}$ & $\mathrm{x}$ & $\mathrm{x}$ & & & & $\mathrm{x}$ & & \\
\hline 10 & 73 & $\mathrm{~F}$ & $\mathrm{x}$ & & & & $\mathrm{x}$ & & $\mathrm{x}$ & & & $\mathrm{x}$ & & & \\
\hline 11 & 72 & $\mathrm{~F}$ & $\mathrm{x}$ & & & & $\mathrm{x}$ & $\mathrm{x}$ & & & & & & & $\mathrm{x}$ \\
\hline 12 & 70 & M & $\mathrm{x}$ & & & & $\mathrm{x}$ & & & $\mathrm{x}$ & & & & & $\mathrm{x}$ \\
\hline 13 & 77 & $\mathrm{~F}$ & $\mathrm{x}$ & & & & $\mathrm{x}$ & & & $\mathrm{x}$ & & $\mathrm{x}$ & & & \\
\hline 14 & 70 & $\mathrm{~F}$ & & $\mathrm{x}$ & & & $\mathrm{x}$ & & & $\mathrm{x}$ & & & $\mathrm{x}$ & & \\
\hline 15 & 74 & $\mathrm{~F}$ & $\mathrm{x}$ & & & & $\mathrm{x}$ & & & $\mathrm{x}$ & & & $\mathrm{x}$ & & \\
\hline 16 & 76 & M & $\mathrm{x}$ & & & & $\mathrm{x}$ & & & $\mathrm{x}$ & & $\mathrm{x}$ & & & \\
\hline $\begin{array}{l}\text { Pt- } \\
\text { deg } \\
\text { deg } \\
\text { No }\end{array}$ & $\begin{array}{l}\text { patient; } \\
\text { ree Mo } \\
\text { ree left } \\
\text { mal- } n\end{array}$ & $\begin{array}{l}\text { Age i } \\
\text { bitz II } \\
\text { bundl } \\
\text { heart }\end{array}$ & $\begin{array}{l}\text { ars; Sy } \\
\text { oventri } \\
\text { anch bl } \\
\text { ease or }\end{array}$ & $\begin{array}{l}\text { syncop } \\
\text { ar bloc } \\
\text {; QRS } \\
\text { e echoc }\end{array}$ & presy & $\begin{array}{l}\text {; Dy } \\
\text { d-deg } \\
\text { com }\end{array}$ & $\begin{array}{l}\text { yspne } \\
\text { sht bi } \\
\text { durati }\end{array}$ & $\begin{array}{l}\text { exertion } \\
\text { branch } \\
\text { orter tha } \\
\text { The " } x\end{array}$ & $\begin{array}{l}\text { asympt } \\
\text { ASDB } \\
\text { millisec } \\
\text { er mean }\end{array}$ & $\begin{array}{l}\text { c; MI- } \\
\text { rosuper } \\
\text { ); SAH- } \\
\text { ence of }\end{array}$ & $\begin{array}{l}\text { ond-deg } \\
\text { division } \\
\text { stemic a } \\
\text { clinical }\end{array}$ & $\begin{array}{l}\text { Tobitz I } \\
\text { ock of t } \\
1 \text { hypert } \\
\text { trocard }\end{array}$ & $\begin{array}{l}\text { ventr } \\
\mathrm{ft} \text { bur } \\
\text { on; } \mathrm{L}\end{array}$ & $\begin{array}{l}\text { ock; I } \\
\text { ch; I } \\
\text { entri }\end{array}$ & $\begin{array}{l}\text { MII- secon } \\
\text { BBB- thir } \\
\text { cular failur }\end{array}$ \\
\hline
\end{tabular}


Seven (44\%) patients had intra-His type 2:1 atrioventricular block, $1(6 \%)$ of whom also had the association of intra- and infra-His bundle block. Two of these 7 patients were asymptomatic.

All patients worsened their block degrees with the increase in the frequency of atrial stimulation. The $\mathrm{H} 2-\mathrm{V}$ interval was normal $(35-45 \mathrm{~ms})^{12}$ in all patients.

Sustained monomorphic ventricular tachycardia was induced in 1 patient $(6 \%)$ with dilated cardiomyopathy and clinical left ventricular failure.

No electrophysiologic difference was found between patients with and without structural cardiomyopathy.

\section{Discussion}

Split-His bundle potentials (H1-H2) occur due to fibrosis in the penetrating region of the His bundle in the central fibrous body ${ }^{6}$, sometimes with a calcific lesion embracing the His bundle and sparing its proximal and distal portion $^{7}$, usually in patients with hypertensive and atherosclerotic diseases.

The fibrotic lesion may extend downward until the formation of the fibers of the left branch, and may even replace the origin of that branch by fibroelastic tissue ${ }^{8}$, which would explain the left bundle-branch on the electrocardiogram.

Anatomicopathological studies in 4 patients, who died due to noncardiac causes and who had been diagnosed with intra-His bundle block on the electrophysiologic study, showed a higher than $50 \%$ reduction in the conduction cells, which were replaced by fibrosis in the most distal portion of the His bundle. The authors considered the $\mathrm{H} 1$ spike of the electrogram of the His bundle originating in the penetrating portion of the His bundle and the $\mathrm{H} 2$ spike originating in the right side of the distal portion of the His bundle ${ }^{9}$.

According to the literature ${ }^{1,3,10,14}$, our series showed that most patients with intra-His bundle block $(68 \%)$ had syncope or presyncope, the minority (12\%) being asymptomatic. The patients most frequently affected by the blocks were the elderly ( $>65$ years) and females.

The old females were more prone to calcific degeneration of the His region due to the involvement of the mitralaortic ring ${ }^{7}$, which occurred 3 times more frequently in females than in males ${ }^{1,3}$. In our case series, the females represented $62.5 \%$ of the patients, and the echocardiographic findings of the mitral-aortic calcific degeneration were considered compatible with age with no signs of significant valvular stenosis or insufficiency. It was not possible to differentiate the predominance of sex in regard to the mitralaortic calcification as a causal factor of intra-His bundle block.

The primary etiology due to degeneration of the conduction system (Lev disease) occurs in many patients ${ }^{2}$. Myocardial infarction may cause acute intra-His bundle block ${ }^{15}$. Some intra-His bundle block are congenital ${ }^{16}$, and others are caused by penetrating wounds ${ }^{17}$ or by surgery ${ }^{16}$. In our case series, 5 patients had hypertensive heart disea- se, 3 had compensated left ventricular failure, 2 of whom had idiopathic dilated cardiomyopathy and 1 had ischemic heart disease, 1 patient had Sjögren's syndrome, and 7 had no structural heart disease.

In autoimmune diseases, such as dermatomyositis, distal block to the His bundle is caused by fibrosis in the distal portion of the left bundle-branch and in the proximal portion of the right bundle-branch with replacement by fibroelastic tissue ${ }^{18}$. In our only young patient ( 25 years) with intra-His bundle block, the underlying disease was Sjögren's syndrome, probably caused by anatomicopathological alterations similar to those of dermatomyositis. In patients younger than 40 years, toxoplasmosis may cause the block ${ }^{19}$.

The chronic use of amiodarone may cause AV nodal ${ }^{20}$, infra-His bundle ${ }^{18}$, or intra-His bundle ${ }^{19}$ blocks in patients with no previous conduction disturbance. None of our patients was using amiodarone during Holter performance or electrophysiologic study ${ }^{21,22}$.

Guimond and Puech ${ }^{3}$ followed up 102 patients with intra-His bundle block and observed the following on the electrophysiologic study: first-degree atrioventricular block in 36 patients $(35.3 \%)$, second-degree atrioventricular block in 23 patients $(22.5 \%$ ), and third-degree atrioventricular block in 43 patients (42.2\%). In the second-degree atrioventricular block group, $70 \%$ of the patients had 2:1 type behavior, $18 \%$ had M I type behavior, and $12 \%$ had M II type behavior. The 2:1 type atrioventricular block is the most common electrocardiographic manifestation of intra-His bundle block ${ }^{3}$ during the electrophysiologic study and it occurred in $44 \%$ of our case series.

According to Narula ${ }^{23}$, second-degree M I atrioventricular block usually has an AV nodal origin ( $72 \%$ of the cases), followed by an infra-His bundle origin ( $21 \%$ of the cases), and, less commonly, an intra-His bundle origin ( $7 \%$ of the cases). Therefore, second-degree M I atrioventricular block does not always have a benign character (intra-nodal $\mathrm{AV})$. Its finding, even with a narrow QRS complex in patients $>50$ years during wakefulness or after an atropine test ${ }^{24}$, should be carefully seen due to the possibility of an intraand infra-His bundle origin for the block. In our case series, second-degree Mobitz I atrioventricular block was present in $4(25 \%)$ patients, 3 with a narrow QRS complex and 1 with right bundle-branch block.

Therefore, in a symptomatic or oligosymptomatic patient with second-degree $\mathrm{MI}$ atrioventricular block with an $\mathrm{A}: \mathrm{V}$ conduction rate of $3: 2$ and $2: 1$ during wakefulness, mainly if the patient is older than 50 years, an electrophysiologic study should be considered.

The second-degree M II atrioventricular block associated with bundle-branch block has an intra-His bundle (35\%) or infra-His bundle $(65 \%)$ lesion. The intra-His bundle block has a narrow QRS complex in $30 \%{ }^{23}$ to $65 \%{ }^{2}$ of the cases. In our study, $50 \%$ of the patients had narrow QRS complex and $50 \%$ had bundle-branch block $(25 \%$ with right bundle-branch block and 25\% with left bundle-branch block). The patients with narrow QRS complex usually had 
an electrocardiographic behavior of second-degree M I atrioventricular block, and those with bundle-branch block had type 2:1 atrioventricular block.

The His bundle has a forward course in the left or right side of the crest of the muscular interventricular septum in $62 \%$ and $16 \%$ of the hearts, respectively ${ }^{24}$, and a greater tendency towards left bundle-branch block than right bundle-branch block exists. However, right bundle-branch block may occur more frequently than left bundle-branch block ${ }^{25}$. This contradiction may be due to the fact that the origin of the fibers, which will form both the right and left branches, follows the anatomic distribution of the His bundle and the lesions in the His bundle occur both in the right and left fibers.

In the series by Guimond and Puech ${ }^{3}, 35 \%$ of the patients had wide QRS complex distributed as follows: isolated right bundle-branch block in $7 \%$ of the patients, right bundle-branch block associated with anterosuperior divisional block in $10 \%$ of the patients, right bundle-branch block associated with posteroinferior divisional block of the left branch (PIDB) in $2 \%$ of the patients, and left bundlebranch block in $16 \%$ of the patients. In the present study, right bundle-branch block was present in $25 \%$ of the cases, half of which were associated with anterosuperior divisional block. This association of right bundle-branch block with anterosuperior divisional block in patients with intraHis bundle block may be due to the proximity, within the His bundle, of the fibers that originate the respective right bundle-branch and the anterosuperior fascicle of the left bundle-branch ${ }^{6,26}$. The close relation of the mitral-aortic ring with the left side of the His bundle (fibers that originate the left bundle-branch) justifies the left bundle-branch block during intra-His bundle block, which occurred in $25 \%$ of our cases. This infiltration occurs in the penetrating portion of the central fibrous body.

The association of atrial arrhythmias (tachycardia, flutter, or fibrillation) and intra-His bundle block is infrequent. It occurred in 5\% of the series by Guimond and Puech $^{3}$, but was not evidenced in ours.

In our case series of 146 patients with second-degree atrioventricular block undergoing electrophysiologic study, we found an $11 \%$ incidence of intra-His bundle block. The infra-His bundle conduction in these patients was normal, in accordance with that in the literature ${ }^{10}$.

Patients with bundle-branch block have a high incidence of cardiac death that may be sudden or due to heart fai- lure, with no relation to the increase in the $\mathrm{H}-\mathrm{V}$ interval ${ }^{27,28}$. The greatest mortality occurs in patients with heart disease and left bundle-branch block and is due to tachycardia or ventricular fibrillation, or both ${ }^{29}$.

Therefore, patients with bundle-branch block should undergo a complete electrophysiologic study including programmed ventricular stimulation, because ventricular arrhythmia may occur in $1 / 3$ to $1 / 2$ of the patients ${ }^{29}$. Occasionally, a patient with intra-His atrioventricular block and structural heart disease may have paroxysmal syncope due to sustained monomorphic ventricular tachycardia ${ }^{29}$. Sustained monomorphic ventricular tachycardia was induced in $6 \%$ of the patients in our case series.

Third-degree atrioventricular block of intra-His origin has an escape heart rate ranging from 30 to $50 \mathrm{bpm}$ with instability of the escape rhythm, which rarely reaches 70 bpm, especially in those surgically induced. Under atropine use or physical activity, heart rate may reach $56 \mathrm{bpm}$, leading most patients to symptoms, such as syncope or dizziness. Occasionally, the patient may be asymptomatic ${ }^{23}$.

Mangiardi et al ${ }^{30}$ followed up 35 patients ( 27 females and 8 males) with intra-His bundle block, all of them with narrow QRS complex, for a period ranging from 12 to 120 months (mean of 45 months). All patients received a definite pacemaker, early for most of them $(90 \%)$, and late for the minority $(10 \%)$.

The mortality rate of patients with intra-His bundle block has not been reported in the literature, which may be explained by definite pacemaker placement, as most patients are highly symptomatic. In this way, we interfere with the natural history of the disease, even though the uncommon asymptomatic cases evolve well with no pacemaker implantation $^{23}$.

Immediately after the electrophysiologic study, all our patients with intra-His bundle block underwent definite pacemaker implantation, and, in a mean 22-month follow-up (18 \pm 10 months), they were asymptomatic.

In conclusion, in our study of patients with intra-His bundle block, syncope and presyncope were the most common (68\%) symptoms. On electrocardiography, we observed normal QRS complex in half of the patients, most of whom (68\%) had second-degree Mobitz I or type 2:1 atrioventricular block. Intra-His bundle block occurred in $11 \%$ of the patients with second-degree atrioventricular block undergoing the electrophysiologic study.

\section{References}

1. Narula OS, Shantha N. Atrioventricular Block: Clinical Concepts and His Bundle Electrocardiography. In: William J Mandel. Cardiac Arrhythmias: Their Mechanisms, Diagnosis \& Management. JB Lippincott Co, 1980: 445-6.

2. Josephson ME. Atrioventricular Conduction. In: Mark E Josephson. Clinical Cardiac Electrophysiology: Techniques and Interpretations, $2^{\text {nd }}$ ed. Lea \& Febinger, 1993: 104-7.

3. Guimond C, Puech P. Intra-His bundle block (102 cases). Eur J Cardiol 1976; 4 481-93.
4. FirmeEP, Andréa EM, Atié J, et al. Experiência em anestesia para procedimentos em eletrofisiologia (abstract). Reblampa 1995; 8: 291-310.

5. Kupersmith J, Krongrad E, Waldo AL. Conduction intervals and conduction vellocity in the human cardiac conduction system. Circulation 1973; 47: 776-80.

6. Rosen KM, Rahimtoola SH, Bharati S, Lev M. Bundle branch block with intact atrioventricular conduction. Am J Cardiol 1973; 32: 783-7.

7. Bharati S, Lev M, Wu D, Denes P, Dhingra RC, Rosen KM. Pathophysiologic correlations in two cases of split His bundle potentials. Ciculation 1974; 49: 615-9. 
8. Bharati S, Lev M, Dhingra RC, Chuquimia R, Towne WD, Rosen KM. Electrphysiologic and pathologic correlations in two cases of chronic second degree atrioventricular block with left bundle branch block. Circulation 1975; 52: 221-4

9. Nakazato Y, Nakata Y, Tokano T, et al. Intr-His bundle block corresponds with interruption of the branching portion of the His bundle. Pacing Clin Electrphysiol 1994; 17: 1124-33.

10. David D, Cabanis C, Guize L, et al. Aspects cliniques et electrophysiologiques des blocs tronculaires hissiens medians a electrocardiogramme de repos normal. Arch Mal Coeur Vaiss 1985; 78: 1009-18.

11. Narula OS, Scherlag BJ, Samet P. His bundle blocks and His bundle rhythms. Dis Chest 1969; 56: 238 .

12. Narula OS. Advances in clinical electrophysiology: Contribution of His bundle recordings. In: Samet P. Cardiac Pacing, ed. New York: Grune \& Stratton, 1973: 331 .

13. Schuilemburg RM, Durrer D. Problems in the recognition of conduction disturbances in the His bundle. Circulation, 1975; 51: 68-73.

14. Rosen KM, Dhingra RC, Loeb HS, Rahimtoola SH. Chronic heart block in adults. Arch Intern Med 1973; 131: 663-6.

15. Rosen KM, Loeb HJ, Chuquimia R, Sinno MZ, Rahimtoola SH, Gumar RM. Site of heart block in acute myocardial infarction. Circulation 1970; 42: 925-30.

16. Nasrallah AT, Gillette PC, Mullins CF. Congenital and surgical atrioventricular block within the His bundle. Am J Cardiol 1975; 36: 914-9.

17. Rosen KM, Heuer R, Ehsani A, Rahimtoola SH. Localization of site of traumatic heart block with His bundle recordings. Am J Cardiol 1972; 30: 412-7.

18. Lighfoot PR, Bharati S, Lev M. Chronic Dermatomyositis with intermitent trifascicular block, na electrophysiologic conduction system correlation. Chest $1977 ; 71: 413-7$
19. Fernandez FG, Maqueda IG, Freire CP, et al. Bloqueo intrahissiano cronico en dos casos de toxoplasmosis. Rev Esp Cardiol 1983; 36: 357-61.

20. Finermam WB, Hamer A, Peter T, Weiss D, Mandel WJ. Electrophysiologic effect of chronic amiodarone therapy in patients with ventricular arrhythmias. Am Heart J 1982; 104: 987-96.

21. Rosenbaum MB, Chiale PA, Halpern MS, et al. Clinical efficacy of amiodarone as na antiarrhythmic agent. Am J Cardiol 1976; 38: 934-44.

22. Kennedy EE, Bastford WP. Amiodarone induced intra-His block. J Am Coll Cardiol 1984; 4: 192-5

23. Narula OS. Cardiac Arrhythmias: Electrophysiology, Diagnosis and Management. Baltimore/London: Williams \& Wilkins, 1979: 85-113.

24. Sumioshi M, Nakata Y, Yasuda M, et al. Clinical and electrophysiologic features of exercise-induced atrioventricular block. Am Heart J 1996; 132: 1277-82.

25. Massing GK, James TN. Anatomical configuration of the His bundle and bundle branches in the human heart. Circulation 1976; 53: 609-13.

26. Narula OS. The manifestation of bundle branch block due to lesions within the His bundle. A dilemma in electrocardiographic interpretations. Chest 1978; 73: 312-5.

27. McAnulty JH, Rahimtoola SH, Murphy E, et al. Natural history of "high-risk" bundle-branch block: final report of a prospective study. N Engl J Med 1982; 307: 137-43.

28. Denes $\mathrm{P}$, Dhingra RC, Wu D, et al. Sudden death in patients with chronic bifascicular block. Arch Intern Med 1977; 137: 1005-9.

29. Ezri M, Lerman BB, Marchlinski FE, et al. Electrophysiologic evaluation of syncope in patients with bifascicular block. Am Heart J 1983; 106: 693-9.

30. Mangiardi LM, Ronzani G, Gaia F, et al. Clinical and electrocardiographic features and long-term results of electrical therapy in patients with isolated His bundle disease. Am Heart J 1986; 112: 1183-91. 